\title{
INFLUENCE OF DIFFERENT LED CURING-UNITS ON DEPTH OF CURE
AND MICRO-HARDNESS OF NANO-HYBRID RESIN COMPOSITE
}

\begin{abstract}
Purpose: To evaluate the effect of two second generation LED Light curing units and a third-generation polywave LED Ligth curing unit at three different irradiation durations on surface microhardness and detpth of cure of nano-hybrid composite resin material.
\end{abstract}

Materials and Methods: Elipar ${ }^{\mathrm{TM}}$ S10, Elipar ${ }^{\mathrm{TM}}$ Deep Cure-S, VALO Cordless, was evaluated at 10s, 20s, 40s curing periods in this study. A nano-hybrid composite Filtek ${ }^{\mathrm{TM}} \mathrm{Z} 550$ that contains camphorquinone as photoinitiator is used as test material. For microhardness test ninety $6 \mathrm{~mm}$ diameter, $4 \mathrm{~mm}$ deep cylindrical composite blocks in teflon molds were prepared. For each light source at each application times 10 specimen were prepared $(n=10)$ and tested. Also ninety, $4 \mathrm{~mm}$ diameter, $6 \mathrm{~mm}$ deep cylindrical composite specimens in a split aluminum mold polymerized with three different light sources at three different durations $(n=10)$ were tested for depth of cure measurement. Data were analyzed statistically by SPSS (Ver: 22.0) one-way ANOVA and multiple comparisons were performed by Tukey's posthoc test. A p-value less than 0.05 was considered statistically significant.

Results: The values of cure depth were found significantly higher at 40 seconds of irradiation time for all light sources used $(\mathrm{p}<0.05)$. Elipar Deep Cure-S showed the higher top surface microhardness at 40s polymerization $(\mathrm{p}<0.05)$

Conclusions: All light devices used in the study provided adequate polymerization of the nano-hybrid composite at all application durations in this study. The highest polymerization depth and microhardness values were achieved at $40 \mathrm{sec}$. polymerization time for all LCUs.

Keywords: Light Curing Unit, Depth of Cure, Micro-Hardness, Deep Cure-S.
ORCID IDs of the authors:
$\begin{array}{ll}\text { A.K. } & 0000-0001-5773-8522 \\ \text { S.K. } & 0000-0003-2601-3064 \\ \text { D.E. } & 0000-0001-8004-7762\end{array}$

1 Department of Restorative Dentistry, Faculty of Dentistry, Sivas Cumhuriyet University, Sivas, Turkey.

2 Department of Restorative Dentistry, Faculty of Dentistry, Alanya Alaaddin Keykubat University, Alanya, Turkey.

Received : 06.01 .2021

Accepted : : 18.02.2021

How to Cite: Kaptan A, Kaya S, Eren D. Influence of Different Led Curing-Units on Depth of Cure and Micro-Hardness of Nano-Hybrid Resin Composite. Cumhuriyet Dent J 2021;24:1:88-95.

*Corresponding Author:

Department of Restorative Dentistry, Faculty of Dentistry, Sivas Cumhuriyet University, Sivas, Turkey.

Phone: +90 34621910 10-3107 Fax: +90 3462191237 $\quad$ E-mail: alperkapdan@ gmail.com 


\section{INTRODUCTION}

Light activated composite resin restorations have become the most preferred restorative materials in the past decade due to their good esthetic properties, mercury-free contents, allow conservative cavity preparation, reinforce of remaining tooth structure, easy application, low cost and low technical sensitivity requirement. ${ }^{1,2}$ Another main advantage is that the working time can be controlled by the operator. ${ }^{3}$ More than two hundred and sixty million resin-based composite restorations are made every year worldwide. ${ }^{4}$ And several studies have reported that the median longevity of posterior resin-based composite (RBC) restorations, is approximately six years., ${ }^{5,6}$ Secondary caries and bulk fractures have been shown as the two common causes of failures., Both this failures may be the result of inadequate photo-polymerization of the RBC. Inadequately photo-cured RBC will exhibit lower degree of conversion which is lead to adverse effects on physical properties and bond strength to preparation walls of RBC restorations., Therefore to avoid these negativities the optimum curing conditions should be provided such as choosing correct light exposure time and irradiance level, precise positioning tip of the light curing unit (LCU) and curing with sufficient energy at correct wavelengths.

The irradiation with the LCU has an important effect on surface hardness and depth of polymerization. ${ }^{10}$ Today there are various LCUs working on different physical principles such as quartz-tungsten-halogen (QTH) bulbs, laser, plasma arc lights, and light emitting diodes (LEDs). Led LCUs has became standard in modern dentistry at the present time due to they have low heat outputs, do not require cooling fan, can be used cordless and they are lighter and smaller. ${ }^{11,12}$ In addition the LED lights efficiency of conversion of electrical energy to curing energy is higher than conventional halogen lamps..$^{13,14}$

Camphorquinone is the most common photoinitiator in the content of RBCs which has absorbtion spectrum of approximately 460-470 $\mathrm{nm}$. LED LCUs provides adequate curing of these composites. Nevertheless some RBCs contain alternative photoinitiators are most sensitive to the lower wavelengths of light below $420 \mathrm{~nm}$, such as diphenyl (2,4,6-trimethylbenzoyl) phosphine oxide (TPO). ${ }^{15,16}$ Today, different light devices are offered for use with different modes that provide higher light output powers. Manufacturers claim that these modes of application provide adequate polymerization in a shorter time.

Surface hardness test has been used in many studies since it is a good indicator of the degree of conversion of composites resin. There is a strong positive correlation between microhardness value and the monomer conversion degree. Depth of cure (DoC) measurement is one another reliably and widely used test to assess the relative degree of cure of RBCs. ${ }^{17}$ According to the ISO 4049 standards DoC of composite resins can be evaluated with placing resin into a $4 \mathrm{~mm}$ diameter $6 \mathrm{~mm}$ depth of a stainless steel mold. ${ }^{16}$ After light polymerization, the uncured composite is removed with a plastic spatula, and the height of the remaining composite is divided in half to determine the DoC. ${ }^{18}$

The aim of the study was to investigate the effect of two second generation LED LCUs and a third-generation polywave LED LCU at three different irradiation durations on surface microhardness and detpth of cure of nano-hybrid composite resin material. The null hypothesis tested was that different light curing devices and different curing periods do not affect polymerization depth and surface hardness.

\section{MATERIALS AND METHODS}

\section{Ethics approval}

Ethical approval was obtained from the Local Ethics Committee of the Sivas Cumhuriyet University, Sivas, Turkey (ID: 2021-02/55).

\section{Restorative Materials and light curing units}

Three different LED LCUs investigated in this study. Selected LCU's for resin polymerization were two second generation LED LCUs (Elipar ${ }^{\mathrm{TM}}$ S10 and Elipar ${ }^{\mathrm{TM}}$ Deep Cure-S; 3M ESPE, St. Paul, MN, USA) and a third-generation LED LCU (VALO Cordless; ULTRADENT, St Louis, MO, USA). A nano-hybrid composite resin (Filtek ${ }^{\mathrm{TM}}$ Z550) used as the restorative material. (Tablo 1,2) 
Table 1. Restorative material used

\begin{tabular}{|c|c|c|c|c|c|}
\hline $\begin{array}{l}\text { Dental resin } \\
\text { composite }\end{array}$ & Manufacturer & Type (Shade) & Composition & $\begin{array}{l}\text { \% Filler } \\
\text { Wt/Vo }\end{array}$ & $\begin{array}{c}\text { Lot } \\
\text { Number }\end{array}$ \\
\hline Filtek Z550 & $\begin{array}{c}\text { 3M ESPE, } \\
\text { St. Paul, MN, USA }\end{array}$ & $\begin{array}{l}\text { Nanohybrid } \\
\text { resin composite, } \\
\text { light-cured, } \\
\text { universal (A2) }\end{array}$ & $\begin{array}{c}\text { Bis-GMA, UDMA, Bis-EMA, } \\
\text { PEGDMA and TEGDMA } \\
\text { Filler: Zirconia/silica, silica } \\
\text { Partical size: } 0.6-10 \mu\end{array}$ & $82 / 68$ & N751485 \\
\hline
\end{tabular}

Table 2. Light Curing Units used in study.

\begin{tabular}{|c|c|c|c|}
\hline $\mathbf{L C U}$ & Manufacturer & $\begin{array}{c}\text { Irradiance stated by } \\
\text { manufacturer }\left(\mathbf{m W} / \mathbf{c m}^{2}\right)\end{array}$ & $\begin{array}{c}\text { Peak Wavelength } \\
(\mathbf{n m})\end{array}$ \\
\hline Elipar $^{\mathrm{TM}} \mathrm{S} 10$ & $\begin{array}{l}\text { 3M ESPE, St Paul, } \\
\text { MN, USA }\end{array}$ & 1200 & $430-480$ \\
\hline Elipar $^{\mathrm{TM}}$ Deep Cure-S & $\begin{array}{l}\text { 3M ESPE, St Paul, } \\
\text { MN, USA }\end{array}$ & 1470 & $430-480$ \\
\hline VALO Cordless & Ultradent & 1400 & $395-480$ \\
\hline
\end{tabular}

\section{Microhardness measurement}

Teflon molds with a circular shaped hole $(6 \mathrm{~mm}$ diameter, $4 \mathrm{~mm}$ deep) was used to prepare samples for microhardness test. After teflon molds placed on a mylar strip and glass slide, composite resin was placed in the molds as it will be two layers. Molds was covered and compressed with another mylar strip and glass slide to provide a flat and smooth surface before polymerization. Three main groups were formed according to the light source used: Group1(Valo): VALO Cordless at $1000 \mathrm{~mW} / \mathrm{cm} 2$, Group 2(Elipar S10): Elipar $^{\mathrm{TM}}$ $\mathrm{S} 10$ at $1200 \mathrm{~mW} / \mathrm{cm} 2$, Group 3(Deep Cure-S): Elipar $^{\mathrm{TM}}$ Deep Cure-S at $1470 \mathrm{~mW} / \mathrm{cm} 2(\mathrm{~N}=30)$. All LCUs used at their standart modes. LED sources was used at three different time intervals $(10 \mathrm{~s}, \quad 20 \mathrm{~s}, \quad 30 \mathrm{~s})$ as a subgroup $(\mathrm{n}=10)$. Polymerization performed with the tip of the light guide $0.5 \mathrm{~mm}$ from the surface of composite resin. Following the polymerization Vickers microhardness test (Shimadzu HMV; Shimadzu Corporation, Tokyo, Japan), was performed at the top (depth=0 $\mathrm{mm}$ ) and bottom (depth=4 $\mathrm{mm}$ ) surfaces of each specimen (three indentations for each specimen), at a 50-g load for 15 seconds.

\section{Depth of cure measurement}

According to the LCUs, three main groups ( $\mathrm{N}=30)$ and for each time period $(10 \mathrm{~s}, 20 \mathrm{~s}, 40 \mathrm{~s})$ three subgroups $\quad(n=10)$ were formed as in microhardness test. A half split aluminum mold with a circular shaped hole (4 mm diameter, $6 \mathrm{~mm}$ deep) was used for depth of cure measurement. Restorative material was placed into the mold and compressed with mylar strip and glass slide from bottom and top to achieve a flat surface. Then the resin was photo-polymerized as in groups. Dept of cure of the composite resin was determined using a standardized technique (ISO 4049:2000). ${ }^{16}$ Immediately after resin polymerization, specimens removed from the mold and uncured material from the bottom scraped away with a plastic spatula. Remaining height of cylinder measured via electronic micrometer to an accuracy of $\pm 0.01 \mathrm{~mm}$ and results divided by two.

\section{Statistical analysis}

The obtained data were analyzed by SPSS (Ver: 22.0) using one-way ANOVA and multiple comparisons were performed by Tukey's posthoc test. A p-value less than 0.05 was considered statistically significant.

\section{RESULTS}

When each light source was evaluated within itself, the difference between the average polymerization depths was not found to be statistically significant at all application periods (10s, 20s, 40s). Deep Cure-S showed highest polymerization depth at $40 \mathrm{~s}$.

Comparison of light sources according to application periods showed that there was no statistical difference between the light sources during the application period of 20 seconds, and $40 \mathrm{~s}$ however there was a difference between the Valo and the other light sources at 10 second. The highest polymerization depth values were observed in Deep Cure-S group at all application times. (Table 3) 
Table 3. Depth of cure means and standard deviations of groups according to irradiation times.

\begin{tabular}{|c|c|c|c|c|}
\hline Gruplar & $\begin{array}{c}\mathbf{1 0} \mathbf{s} \\
\overline{\mathbf{x}} \pm \mathbf{s S} \\
\end{array}$ & $\begin{array}{c}20 \mathrm{~s} \\
\overline{\mathbf{x}} \pm \mathbf{s S} \\
\end{array}$ & $\begin{array}{c}40 \mathrm{~s} \\
\overline{\mathrm{x}} \pm \mathrm{SS} \\
\end{array}$ & \\
\hline Valo & $1.849 \pm 0.121^{\mathrm{A}, \mathrm{a}}$ & $2.002 \pm 0.167^{\mathrm{A}, \mathrm{a}}$ & $2.516 \pm 0.072^{\mathrm{A}, \mathrm{b}}$ & $\mathrm{F}=69.1 \mathrm{p}=0.001 *$ \\
\hline Elipar S10 & $2.042 \pm 0.116^{\mathrm{B}, \mathrm{a}}$ & $2.217 \pm 0.164^{\mathrm{A}, \mathrm{a}}$ & $2.678 \pm 0.202^{\mathrm{A}, \mathrm{b}}$ & $\mathrm{F}=38.39 \mathrm{p}=0.001 *$ \\
\hline \multirow[t]{2}{*}{ Deep cure-S } & $2.078 \pm 0.093^{\mathrm{B}, \mathrm{a}}$ & $2.153 \pm 0.245^{\mathrm{A}, \mathrm{a}}$ & $2.699 \pm 0.177^{\mathrm{A}, \mathrm{b}}$ & $\mathrm{F}=34.82 \mathrm{p}=0.001 *$ \\
\hline & $\mathrm{F}=12.27 \mathrm{p}=0.001^{*}$ & $\mathrm{~F}=3.60 \mathrm{p}=0.058$ & $\mathrm{~F}=3.87 \mathrm{p}=0.063$ & \\
\hline
\end{tabular}

In each column, groups with the same capital superscripts are not significantly different and in each row, groups with the same lower case superscripts are not significantly different $(\mathrm{p}>0.05)$.

For each light source, mean top surface microhardness values at 40 s was found higer than 20s and 10s. However only in Deep Cure-S group 20s, 40s microhardness values were significantly higher than 10s. The highest surface hardness was found in Deep Cure-S group at 40s. When the light sources were compared according to the duration of application, no statistically difference was observed between the light sources in all application periods. (Table 4)

Table 4. Top $(0 \mathrm{~mm})$ surface microhardness means and standard deviations of groups according to irradiation times

\begin{tabular}{|c|c|c|c|c|}
\hline Gruplar & $\begin{array}{c}\mathbf{1 0} \mathbf{s} \\
\overline{\mathbf{x}} \pm \mathbf{s S} \\
\end{array}$ & $\begin{array}{l}\mathbf{2 0 ~ S} \\
\overline{\mathbf{x}} \pm \mathbf{S S} \\
\end{array}$ & $\begin{array}{l}\mathbf{4 0 ~ s} \\
\overline{\mathrm{x}} \pm \mathrm{SS} \\
\end{array}$ & \\
\hline Valo & $98.937 \pm 5.021^{\mathrm{A}, \mathrm{a}}$ & $98.712 \pm 4.606^{\mathrm{A}, \mathrm{a}}$ & $98.875 \pm 7.088^{\mathrm{A}, \mathrm{a}}$ & $\mathrm{F}=0.001 \mathrm{p}=0.994$ \\
\hline Elipar S10 & $96.850 \pm 4.415^{\mathrm{A}, \mathrm{a}}$ & $96.175 \pm 5.132^{\mathrm{A}, \mathrm{a}}$ & $99.300 \pm 2.931^{\mathrm{A}, \mathrm{a}}$ & $\mathrm{F}=1.33 \mathrm{p}=0.295$ \\
\hline \multirow[t]{2}{*}{ Deep cure-S } & $94.387 \pm 7.170^{\mathrm{A}, \mathrm{a}}$ & $104.075 \pm 5.539^{\mathrm{A}, \mathrm{b}}$ & $106.037 \pm 6.215^{\mathrm{A}, \mathrm{b}}$ & $\mathrm{F}=6.29 \mathrm{p}=0.011^{*}$ \\
\hline & $\mathrm{F}=1.29 \mathrm{p}=0.295$ & $\mathrm{~F}=4.99 \mathrm{p}=0.506$ & $\mathrm{~F}=13.97 \mathrm{p}=0.054$ & \\
\hline
\end{tabular}

In each column, groups with the same capital superscripts are not significantly different and in each row, groups with the same lower case superscripts are not significantly different $(\mathrm{p}>0.05)$.

According to bottom surface microhardness values in Valo and Elipar S10 groups examined after 20s and 40s curing, microhardness values were significantly higher than 10 s curing duration. The highest bottom surface hardness value was found in Deep Cure-S group at 40s. As aresult of examination of light sources according to the duration of application, there was statistically difference between the light sources in the $40 \mathrm{~s}$ period, but no statistically difference between the light sources at the $10 \mathrm{~s}$ and 20s. (Table 5)

Table 5. Bottom (4 mm) surface microhardness means and standard deviations of groups according to irradiation times

\begin{tabular}{|c|c|c|c|c|}
\hline Gruplar & $\begin{array}{c}10 \mathrm{~s} \\
\overline{\mathbf{x}} \pm \mathbf{s S}\end{array}$ & $\begin{array}{l}\mathbf{2 0 ~ s} \\
\overline{\mathbf{x}} \pm \mathrm{sS} \\
\end{array}$ & $\begin{array}{l}40 \mathrm{~s} \\
\overline{\mathrm{X}} \pm \mathrm{SS}\end{array}$ & \\
\hline Valo & $83.437 \pm 6.166^{\mathrm{A}, \mathrm{a}}$ & $90.275 \pm 4.715^{\mathrm{A}, \mathrm{b}}$ & $92.262 \pm 5.269^{\mathrm{A}, \mathrm{b}}$ & $\begin{array}{c}\mathrm{F}=7.59 \\
\mathrm{p}=0.005^{*}\end{array}$ \\
\hline Elipar S10 & $86.137 \pm 5,773^{\mathrm{A}, \mathrm{a}}$ & $93.787 \pm 5.352^{\mathrm{A}, \mathrm{b}}$ & $94.112 \pm 3.171^{\mathrm{A}, \mathrm{b}}$ & $\begin{array}{l}\mathrm{F}=6.58 \\
\mathrm{p}=0,008 *\end{array}$ \\
\hline \multirow[t]{2}{*}{ Deep cure-S } & $86.137 \pm 3.381^{\mathrm{A}, \mathrm{a}}$ & $95.150 \pm 5.262^{\mathrm{A}, \mathrm{b}}$ & $104.525 \pm 5.121^{\mathrm{B}, \mathrm{c}}$ & $\begin{array}{l}\mathrm{F}=30.85 \\
\mathrm{p}=0.001 *\end{array}$ \\
\hline & $\mathrm{F}=0.70 \mathrm{p}=0.506$ & $\mathrm{~F}=1.92 \mathrm{p}=0.506$ & $\mathrm{~F}=16.37 \mathrm{p}=0.001 *$ & \\
\hline
\end{tabular}

In each column, groups with the same capital superscripts are not significantly different and in each row, groups with the same lower case superscripts are not significantly different $(p>0.05)$.

Bottom and top surface hardnesses of the groups were compared within each application period and the results showed that the mean surface hardness values of the bottom and top surface of S10 group at 20s and Deep Cure-S group at 40s were found to be statistically insignificant. Mean hardness values of lower and upper surface of all other groups were found to be statistically significant. (Table 6) 
Table 6. Microhardness means and standard deviations of top $(0 \mathrm{~mm})$ and bottom $(4 \mathrm{~mm})$ surfaces of groups according to irradiation times.

\begin{tabular}{lclll}
\hline \multicolumn{1}{c}{ Groups } & $\begin{array}{c}\text { Irradiation time/ } \\
\text { detpth }(\mathbf{m m})\end{array}$ & \multicolumn{1}{c}{ Means } & Standart deviation & \\
\hline VALO & $10 \mathrm{~s} / 4 \mathrm{~mm}$ & $83.4375^{\mathrm{a}}$ & 6.16695 & $\mathrm{t}=7.90$ \\
& $10 \mathrm{~s} / 0 \mathrm{~mm}$ & $98.9375^{\mathrm{b}}$ & 5.02165 & $\mathrm{P}=0.001^{*}$ \\
& $20 \mathrm{~s} / 4 \mathrm{~mm}$ & $90.275^{\mathrm{a}}$ & 4.71525 & $\mathrm{t}=7.20$ \\
& $20 \mathrm{~s} / 0 \mathrm{~mm}$ & $98.7125^{\mathrm{b}}$ & 4.60665 & $\mathrm{P}=0.001^{*}$ \\
& $40 \mathrm{~s} / 4 \mathrm{~mm}$ & $92.2625^{\mathrm{a}}$ & 5.26957 & $\mathrm{t}=3.44$ \\
& $40 \mathrm{~s} / 0 \mathrm{~mm}$ & $98.875^{\mathrm{b}}$ & 7.08877 & $\mathrm{P}=0.011^{*}$ \\
\hline Elipar S10 & $10 \mathrm{~s} / 4 \mathrm{~mm}$ & $86.1375^{\mathrm{a}}$ & 5.77307 & $\mathrm{t}=4.49$ \\
& $10 \mathrm{~s} / 0 \mathrm{~mm}$ & $96.85^{\mathrm{b}}$ & 4.41523 & $\mathrm{P}=0.003^{*}$ \\
& $20 \mathrm{~s} / 4 \mathrm{~mm}$ & $93.7875^{\mathrm{a}}$ & 5.35255 & $\mathrm{t}=0.86$ \\
& $20 \mathrm{~s} / 0 \mathrm{~mm}$ & $96.175^{\mathrm{a}}$ & 5.13218 & $\mathrm{P}=0.415$ \\
& $40 \mathrm{~s} / 4 \mathrm{~mm}$ & $94.1125^{\mathrm{a}}$ & 3.17105 & $\mathrm{t}=2.74$ \\
& $40 \mathrm{~s} / 0 \mathrm{~mm}$ & $96.321^{\mathrm{a}}$ & 2.9316 & $\mathrm{P}=0.029$ \\
\hline Deep Cure-S & $10 \mathrm{~s} / 4 \mathrm{~mm}$ & $86.1375^{\mathrm{a}}$ & 3.38186 & $\mathrm{t}=3.05$ \\
& $10 \mathrm{~s} / 0 \mathrm{~mm}$ & $94.3875^{\mathrm{b}}$ & 7.17026 & $\mathrm{P}=0.015^{*}$ \\
& $20 \mathrm{~s} / 4 \mathrm{~mm}$ & $95.15^{\mathrm{a}}$ & 5.26254 & $\mathrm{t}=3.60$ \\
& $20 \mathrm{~s} / 0 \mathrm{~mm}$ & $104.075^{\mathrm{b}}$ & 5.53966 & $\mathrm{P}=0.009^{*}$ \\
& $40 \mathrm{~s} / 4 \mathrm{~mm}$ & $104.525^{\mathrm{a}}$ & 5.12187 & $\mathrm{t}=0.71$ \\
& $40 \mathrm{~s} / 0 \mathrm{~mm}$ & $106.0375^{\mathrm{a}}$ & 6.2154 & $\mathrm{P}=0.496$ \\
\hline
\end{tabular}

The same lower case superscripts in each column indicate no statistically significant difference between groups.

$\mathrm{P}$ values in the last column indicate t-test's results.

$* \mathrm{P}<0.05$.

\section{DISCUSSION}

Adequate polymerization is one of the main important factors influencing the physical and mechanical properties of composite resins. Degree of conversion and depth of cure analyzes are important tools to estimate the physical and mechanical properties of composite resin restorations. $^{18,19}$ Microhardness evaluation at specific depths is a widely used method to determine the depth of polymerization of resinbased restorative materials. For adequate polymerization depth, it is recommended that the bottom surface hardness is about $80 \%$ of the upper surface hardness value. ${ }^{20,21}$

Also another standardized technique defined by ISO 4049 standard has been used determining of cure depth. The ISO 4049 standard evaluates DOC by placing composite resin into a $6 \mathrm{~mm}$ deep and $4 \mathrm{~mm}$ diameter opening of a split stainless steel mold. Immediately after light polymerization, the uncured resin material is removed with a plastic spatula, the height of the remaining composite is divided in half. These values recorded as the ISO depth of cure must be higher than $1.5 \mathrm{~mm} .{ }^{18,22}$

The irradiation time is very important for optimum polymerization of the resin at increased depth, although there is no major factor in the polymerization at the surface. ${ }^{23}$ Time-saving applications are an ongoing request for restorative practices and significant improvements in technology of LED light sources allow shorter clinical application times. ${ }^{12,24}$ Some recent studies have emphasized the potential of these LED curing lights to reduce the irradiation time without a significant loss in the mechanical properties of the RBCs. ${ }^{23,25}$

In this study, microhardness and polymerization depths of a camphorquinone photo-initiator containing resin-based composite material that photo polymerized with two different 
second generation and a third generation LED light sources at three different irradiation times were evaluated.

The null hypothesis was partially rejected because there are significant differences between the light curing periods in terms of polymerization depth and surface hardness however the top surface hardness values of Valo and S10 groups has showed no statistically changes at 10 s and 20 s light curing periods $(\mathrm{p}>0.05)$. And also DeepCureS-40s subgroup has showed significantly higher top and bottom surface hardness values than other LCUs $(\mathrm{p}<0.05)$.

Although all the LCUs perform adequate polymerization depth according to ISO 4049 depth of cure measurement (scraping test) at the $10 \mathrm{~s}$ irradiation time, VALO group showed statistically lower polymerization depth values than the other groups $(\mathrm{p}<0.05)$. This difference may be due to using VALO Cordless at 1000 $\mathrm{mW} / \mathrm{cm}^{2}$ output power so three light sources has a $1.2 \mathrm{x}-1.47 \mathrm{x}$ difference in the emitted power depending on the brand of LCU. In addition VALO has a different structural design of tip than the other light sources that may lead less polymerization at $10 \mathrm{~s}$.

In a study evaluating the effects of Elipar DeepCure-S and Valo LCUs on the amount of residual monomer released from different composites; the amount of residual monomer released from composites polymerized with the Elipar DeepCure-S light device was found to be less than the groups polymerized with the Valo light device, similar to our study. ${ }^{26}$ In another study investigating the effect of LCUs on the bonding strength in the repair of different composites with bulk-fill composites, the Elipar DeepCure-S provided better bonding strength than the Valo light device, and this was attributed to the Elipar DeepCure-S light device providing better polymerization at the bottom of the composite. $^{27}$

All light curing units used in the study has provided significantly high polymerization depths at 40 second compared to 10 and 20 seconds $(\mathrm{p}<0.05)$. This can be explained by prolonged curing times allow the formation of additional cross-links in higher depths of restorative material and lead to a more homogeneous polymer network. ${ }^{10}$ In addition, although shortened light curing durations provide sufficient polymerization, radiant exposure of the restorative material at $40 \mathrm{~s}$ light curing mode will be more than shorten curing times. ${ }^{21}$ Altough there is a slightly difference of output powers of LCUs there was no statistically significant difference was found between the DoC values when comparing the depth of polymerization of the LCUs at the 20s and 40s periods. This has shown that the increased polymerization time can compensate the output power difference between the LCUs at used parameters.

When the surface microhardness values were compared, there was no difference in microhardness between the irradiation times in the Valo and Elipars S10 groups, while an increase in the exposure times of 20 and 40 seconds was observed in the Deep Cure-S group. This result can be explained by the fact that the energy output power of the Deep Cure S device is higher than the other devices $(1470 \mathrm{~nm} / \mathrm{cm} 2)$ and different optical tip design. Differences in tip area can causea large effect on the calculated radiation. ${ }^{16,28}$

The bottom microhardness results of the groups showed that 20 s and 40 s irradiation values are higher than $10 \mathrm{~s}$ groups in all devices. However, in the Deep Cure-S group, there is no statistically significant difference between the surface and bottom microhardness values of the nanohybrid composite at 40 s irradiation time. This can be explaned that light beam profile of Deep Cure-S deeper and more homegenous then the other light sources used. ${ }^{16,28}$

\section{CONCLUSIONS}

All light sources used in this study provide adequate polymerization of the nanohybrid composite which includes camphorquinone as a photoinitiator in all application time mods. The highest polymerization depth and microhardness values were achieved with $40 \mathrm{sec}$. polymerization time for all LCUs and Deep Cures S light devive provided statisticaly same microharnes values between top an bottom surfaces at 40s. 


\section{ACKNOWLEDGMENTS}

The authors thank to Dr Ziynet Çınar for her assistance with the statistical analysis.

\section{CONFLICT OF INTEREST}

There is no conflict of interest.

\section{REFERENCES}

1. Firouzmandi M, Doozandeh M, Jowkar Z, Abbasi S. Effect of composite/amalgam thickness on fracture resistance of maxillary premolar teeth, restored with combined amalgam-composite restorations. J Clin Exp Dent 2016;8:e268-272.

2. Kemaloglu H, Pamir T, Tezel H. A 3-year randomized clinical trial evaluating two different bonded posterior restorations: Amalgam versus resin composite. Eur J Dent 2016;10:16-22.

3. Dietschi D, Marret N, Krejci I. Comparative efficiency of plasma and halogen light sources on composite micro-hardness in different curing conditions. Dent Mater 2003;19:493-500.

4. Heintze SD, Rousson V. Clinical effectiveness of direct class II restorations - a meta-analysis. J Adhes Dent 2012;14:407-431.

5. Sunnegardh-Gronberg K, van Dijken JW, Funegard U, Lindberg A, Nilsson M. Selection of dental materials and longevity of replaced restorations in Public Dental Health clinics in northern Sweden. J Dent 2009;37:673-678.

6. Rho YJ, Namgung C, Jin BH, Lim BS, Cho BH. Longevity of direct restorations in stress-bearing posterior cavities: a retrospective study. Oper Dent 2013;38:572-582.

7. Rasines Alcaraz MG, Veitz-Keenan A, Sahrmann P, Schmidlin PR, Davis D, Iheozor-Ejiofor Z. Direct composite resin fillings versus amalgam fillings for permanent or adult posterior teeth. Cochrane Database Syst Rev 2014;3.

8. Hammouda IM. Effect of light-curing method on wear and hardness of composite resin. J Mech Behav Biomed Mater 2010;3:216-222.

9. Ferracane JL, Berge HX, Condon JR. In vitro aging of dental composites in water--effect of degree of conversion, filler volume, and filler/matrix coupling. J Biomed Mater Res 1998;42:465-472.
10. Haenel T, Hausnerova B, Steinhaus J, Price RB, Sullivan B, Moeginger B. Effect of the irradiance distribution from light curing units on the local microhardness of the surface of dental resins. Dent Mater 2015;31:93-104.

11. Jandt KD, Mills RW. A brief history of LED photopolymerization. Dent Mater 2013;29:605-617.

12. Gonulol N, Ozer S, Tunc ES. Effect of a thirdgeneration LED LCU on microhardness of toothcolored restorative materials. Int $\mathrm{J}$ Paediatr Dent 2016;26:376-382.

13. Yaman BC, Efes BG, Dorter C, Gomec Y, Erdilek D, Buyukgokcesu S. The effects of halogen and lightemitting diode light curing on the depth of cure and surface microhardness of composite resins. J Conserv Dent 2011;14:136-139.

14. Tsai PC, Meyers IA, Walsh LJ. Depth of cure and surface microhardness of composite resin cured with blue LED curing lights. Dent Mater 2004;20:364-369.

15. de Oliveira DC, Rocha MG, Correa IC, Correr AB, Ferracane JL, Sinhoreti MA. The effect of combining photoinitiator systems on the color and curing profile of resin-based composites. Dent Mater 2016;32:12091217.

16. Shimokawa CA, Turbino ML, Harlow JE, Price HL, Price RB. Light output from six battery operated dental curing lights. Mater Sci Eng C Mater Biol Appl 2016;69:1036-1042.

17. Agrawal A, Manwar NU, Hegde SG, Chandak M, Ikhar A, Patel A. Comparative evaluation of surface hardness and depth of cure of silorane and methacrylate-based posterior composite resins: An in vitro study. J Conserv Dent 2015;18:136-139.

18. Menees TS, Lin CP, Kojic DD, Burgess JO, Lawson NC. Depth of cure of bulk fill composites with monowave and polywave curing lights. Am J Dent 2015;28:357-361.

19. Alshali RZ, Silikas N, Satterthwaite JD. Degree of conversion of bulk-fill compared to conventional resincomposites at two time intervals. Dent Mater 2013;29:e213-217.

20. Mousavinasab SM, Meyers I. Comparison of Depth of Cure, Hardness and Heat Generation of LED and 
High Intensity QTH Light Sources. Eur J Dent 2011;5:299-304.

21. MM AL, Haenel T, Sullivan B, Labrie D, Alqahtani MQ, Price RB. Effect of a broad-spectrum LED curing light on the Knoop microhardness of four posterior resin based composites at 2, 4 and 6-mm depths. J Dent 2016;45:14-18.

22. de Moraes Porto IC, Ramos de Brito AC, Parolia A. Effect of cross infection control barriers used on the light-curing device tips on the cure depth of a resin composite. J Conserv Dent 2013;16:224-228.

23. Leprince J, Devaux J, Mullier T, Vreven J, Leloup G. Pulpal-temperature rise and polymerization efficiency of LED curing lights. Oper Dent 2010;35:220-230.

24. Roberts HW, Berzins DW, Charlton DG. Hardness of three resin-modified glass-ionomer restorative materials as a function of depth and time. J Esthet Restor Dent 2009;21:262-272.
25. Campregher UB, Samuel SM, Fortes CB, Medina AD, Collares FM, Ogliari FA. Effectiveness of secondgeneration light-emitting diode (LED) light curing units. J Contemp Dent Pract 2007;8:35-42.

26. Hürmüzlü F, Kılıç V. Analysis of Monomer Elution from Bulk-fill and Nanocomposites Cured with Different Light Curing Units Using High Performance Liquid Chromatography. J Photopolym Sci Technol 2020;33:27-36.

27. Kilic V, Hürmüzlü F. Effect of Light Sources on Bond Strength of Different Composite Resins Repaired with Bulk-Fill Composite. Odovtos-Int J Dent Sc 2021;23:103-115.

28. Shimokawa CAK, Turbino ML, Giannini M, Braga RR, Price RB. Effect of light curing units on the polymerization of bulk fill resin-based composites. Dent Mater 2018;34:1211-1221. 